treated in the ordinary way. Constipation as a symptom does not need to be treated, as it soon passes away when the child retains its food. Warmth is most essential for the child as evidenced by the subnormal temperature so constantly present. Although this class of case is uncommon it would seem not improbable that a certain proportion of them may recover under suitable treatment.

Bibliography.-Cautley: Transactions of the Royal Medical and Chirurgical Society, vol. 1xxxii., p. 41, 1899. Rolleston and Hayne : Brit. Med. Jour., April, 1898. Finkelstein: Jahrbuch für Kinderheilkunde, Band 48, S. 105. Senator: Berliner Klinische Wochenschrift, 1897, S. 43. Still: Transactions of the Pathological Society of London, 1899. Thomson: Edinburgh Hospital Reports, vol. iv.; Scottish Medical and Surgical Journal, June, 1897

Harley-street, W.

\section{A CASE OF LATERAL TRANSPOSITION OF THE VISCERA.}

BY J. HARLEY BROOKS, M.D. ABERD., ASSTSTANT MEDICAL OFFICER TO THE MTLE HND INFIRMARY WORKHOUSE AND SCHOOLS.

A MAN, aged 67 years, was admitted into Mile End Infirmary on Oct. 24th and was found to be suffering from fractured ribs, and pleurisy and pneumonia followed, causing his death on Oct. 30th. It was alleged that while in a public-house on Oct. 8th he received a violent blow in his side and to this he attributed his illness. It became necessary to take his depositions and this was done in the presence of a man who had been arrested on a charge of causing him grievous bodily harm.

At the post-mortem examination a bruise that might very well have been produced by a violent blow was found in the right loin embracing the two floating ribs, while the fractured ribs were the ninth and tenth. A blow received in the position located by the bruise resulting in the fracture of the injured ribs, I pointed out at the inquest, must have been delivered in an upward direction and also have been so violent a blow as to push aside the floating ribs and crash

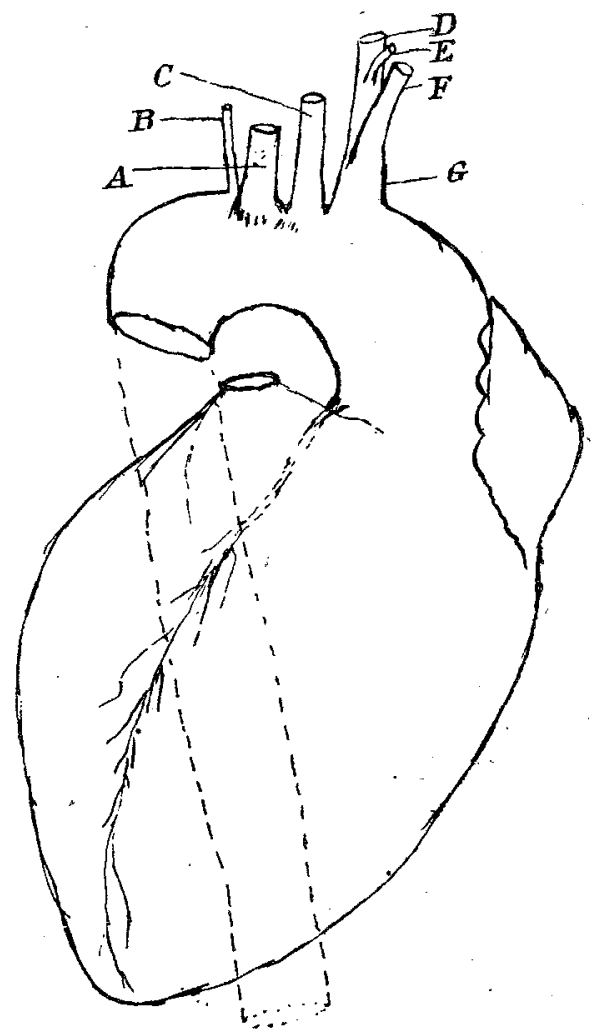
artery B given off direetly from the aorta leyond the right artery $B$ given off direetly from the aorta beyond the right subclavian artery $A^{A}$. The left vertebral artery E rises from the front of the left subclavian artery o. c marks the right innominate artery.

through the ninth and tenth ribs. The evidence as to the deceased having received the alleged blow was conflicting and there was an admission by the deceased of a fall down the stairs which might readily have produced the fracture, so the coroner's jury very wisely returned an open verdict.
Interesting as the necropsy was from the medico-legal aspect it proved of still greater interest from an anatomical point of view, for I found that curious abnormality-transposition of the viscera. On opening the body I first noticed that the spleen was on the right side and $I$ then found that the liver was occupying the left hypochondriac region. 'The crcum and vermiform appendix were not in the usual site but had been transposed to the left, and the colon followed a reverse course to the normal, the sigmoid flexure being in the right iliac region. As regards the kidneys there was nothing to identify the one from the other apart from their respective weights, the one on the left being the heavier, but the pathological changes were sufficient to account for the variation in weight. The stomach, rather a small one, was transposed, the cardiac orifice being to the right and the pyloric to the left. The duodenum was very much dilated and at first sight it seemed almost as though it were a second stomach; however, this proved not to be the case. The pancreas also took part in the general transposition. In fact, the abdominal viscera exhibited the appearance described by others who have recorded cases-as though the normal arrangement were viewed in a mirror. In the thorax this method of description apparently applied so far as the disposition of the heart and lungs was concerned, the left lung being the right one transposed, as evidenced by its three lobes, and the one on the right with only two lobes being the left lung on the wrong side of the body. The blood-vessels springing from the arch, however, were not merely transposed along with the aorta: they came off from the left to the right as innominate, right common carotid, right subclavian, and as a variation not unknown - the right vertebral artery sprang directly from the arch somewhat behind but a little to the right of the subclavian. The innominate divided into the left subclavian and the left carotid, the latter lying directly in front of the former. The left vertebral artery arose from the anterior aspect of the left subclavian instead of from the posterior about half an inch above the bifurcation of the innominate, hidden from view by the overlapping carotid artery. The aorta and the csophagus lay to the right of the vertebral column. The patient was right-handed.

It is a curious coincidence that one of the cases of transposition of viscera recorded by Dr. Pye-Smith ${ }^{1}$ was that of an old woman from Mile End Workhouse.

Mile End Infirmary, Bancroft-road, N.E.

\section{Clinical atotes:}

\section{MEDICAL, SURGICAL, OBSTETRICAL, AND THERAPEUTICAL.}

\section{NOTE ON A FATAL CASE OF DOUBLE STRANGU- LATED FEMORAL HERNIA.}

By Walter Falla, L.R.C.P. LOND., M.R.C.S. ENG., SURGEON TO THE JERSEY GEXERAL FOSPITAT.

ON Oct. 31st last I was called to attend a woman, aged 65 years. She had previously always enjoyed good health. I found her in a very weak state and on inquiry I ascertained that she had had symptoms of intestinal obstruction for four days ; the vomiting was very persistent and was quite fæcal. On examination $I$ found two femoral hernix, both of which were irreducible. The patient stated that she had had a swelling in the left groin for four months and that a similar swelling had come on suddenly on the previous day on the right side. After a consultation with Dr. A. C. Godfray at 4 P.M. an immediate operation was decided upon. Dr. Godfray kindly assisted me while Dr. T. J. Aubin administered chloroform. On the left side after opening the sac we found a gangrenous piece of omentum which I excised, and on opening the sac on the right side we found a portion of intestine very much congested and tightly strangulated which was easily reduced after dividing the neck of the sac, and the operation was concluded in the usual way. On the following morning the patient, although weak, appeared to be doing well and had 
passed flatus per rectum freely during the night, but unfortunately in the evening vomiting recurred and she died 36 hours after the operation.

This case is interesting chiefly on account of the rarity of its occurrence. The right hernia and its subsequent strangulation seem to have been caused by the violent efforts of vomiting after the left hernia had become strangulated, and the unfortunate result must to a great extent be attributed to the unavoidably long delay before operating.

Jersey.

\section{A SYMMETRICAL PALMAR ERYTHEMA.}

By Albert J. Chalmers, M.D. Viot., F.R.C.S. ENG., ASSISTANT COLONIAL SURGEON, THE GOLD COAST COLONY, WEST AFRICA.

A SYMMETRICAL erythema affecting the ulnar side of the palms of both hands is extremely common among Europeans residing on the Gold Coast of West Africa, and though a trivial matter I have thought it worth recording.

The erythema is symmetrical, affecting the ulnar side of the palm and the hypothenar eminence. The typical affection extends from the position of the pisiform and hook of the unciform to the base of the little finger, with a breadth of about one inch in its widest part. Sometimes it also affects the ulnar border of the hand, to which occasionally it is confined. In less marked cases it may extend only half way to the base of the little finger or it may be confined to only a portion of the hypothenar eminence. In colour it varies from a slight blush up to a vivid scarlet red, but in its more typical form it is a bright red. Though persistent, yet it varies a little from time to time. There is no evident abnormal thickening of the skin in this region, though small scales are sometimes to be seen. The apertures of the sweatducts do not appear to be more open than usual and the affected part does not perspire more than the rest of the palm. It causes no symptoms and never, so far as I know, goes on to eczema. It requires no treatment.

The causation of this little affection appears to be obscure. It is true that it is in the area of the hand supplied by the ulnar nerve, but it does not affect. the whole of that part nor does it appear to restrict itself to the cutaneous area of the palmar branch of that nerve.

The interest attaching to this erythema is that it is symmetrical in both hands and persistent and that a number of the Europeans residing here have it. It is to be distinguished from the "erythema keratodes" described by Dr. Brooke, in that it does not lead to an overgrowth of the horny tissue or to œdema or tenderness; it is likewise distinct from the "keratodermia erythematosa symmetrica" of Besnier.

I am permitted to publish this note by the kind permission of his Fxcellency Sir Frederick Hodgson, K.C.M.G., Governor of the Gold Coast Colony.

Gold Coast, West Africa.

DEATH FROM DISLOCATION BETWEEN THE ATLAS AND AXIS.

By Harry Hollis, M.D. CAMb

ABouT midnight on Oct. 7th, 1899, a man with his wife and baby were on their way from Wellingborough to Finedon, a village four miles distant. They were both drunk and, according to many witnesses, the man frequently threatened to kill his wife. One witness even took away a razor with which the man said he would cut his wife's throat. A mile from Wellingborough they slept under a haystack. Between 5 and 6 A.M. on Oct. 8th the woman's dead body was found on the side of the road 60 yards from the stack; there was a distinct track from the end of the stack to the place where the woman was found, evidently caused by her being dragged along the ground. The man after going to some cottages close by went to the Wellingborough police-station and told the police that his wife was dead.

A post-mortem examination was made by my partner $(\mathrm{Mr}$. W. E. Audland) and misself on the same morning. There were large and severe ecchymoses on the face and lower jaw and in various parts of the body. There was extravasation of blood in the left temporal muscle and in the scalp over the left frontal and parietal regions. The surface of the brain beneath was ecchymosed, and on cutting the brain its substance to a depth of a quarter of an inch was much redder than the corresponding part of the right side. On the left side there was extravasation of blood in the deep cervical muscles on a level with the fifth vertebra. There was a separation posteriorly between the atlas and axis, with rupture of the posterior atlanto-axial ligament. The separation was sufficient to allow the forefinger to touch the spinal cord. There was no fracture and no displacement of the odontoid process, nor was there any damage, macroscopic or microscopic, to the spinal cord. The larynx contained a small quantity of bloody mucus. The right side of the heart was full of blood; the left side was empty. Both kidneys, especially the right, were engorged with blood; all of the other organs of the body were healthy. Urine and fæces had been expelled, the linen was not stained as if by bloody urine ; the bladder was empty.

At the inquest, and subsequently at the Northampton Assizes, I gave it as my opinion, and $\mathrm{Mr}$. Audland agreed with me, that death was caused by the dislocation between the atlas and axis caused probably in an attempt to throttle, the chin being forced downwards and backwards, while the head was either pulled forwards or resting on something solid. The defence did not deny that death was caused by dislocation, but suggested that it took place accidentally while the woman was being dragged into the road, she at the time being unconscious from the effect of the injury to the head. The man was found guilty of manslaughter and was sentenced to 15 years' penal servitude.

The points of interest are that there was damage to the brain on the same side as there had evidently been a blow or a fall, and that there was no hæmorrhage in the spinal canal or damage to the cord, although the expulsion of urine and fæces together with the condition of the kidneys point to the dislocation as the cause of death.

Wellingborough.

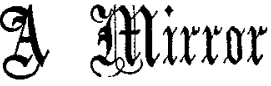

OF

\section{HOSPITAL PRACTICE,}

\section{BRITISH AND FOREIGN.}

Nulla autem est alia pro certo noscendi via, nisi quamplurimas et morborum et dissectionum historias, tum aliorum tum proprias collectas habere, et inter se comparare.-MoRGAGNI De Sed. et Caus. Mlorb., lib. iv. Proomium.

\section{WESTMINSTER HOSPITAL.}

\section{A CASE OF EXTENSIVE CONGENTTAL AND ACQUIRED} HEART DISEASE.

(Under the care of Dr. F. DE Havilland HaLL.)

For the notes of this case we are indebted to Mr. Reginald Nitch-Smith, late house physician.

A young woman, aged 18 years, was transferred from the gynxocological to the medical wards of the Westminster Hospital, under the care of Dr. de Havilland Hall. When she was admitted she complained of pain all down the left side. About four months before admission she was suddenly seized with pain in the left side, but she was able to keep at work. The pain was severe for a few days and then disappeared. She had no recurrence till Dec. 19th, 1895, when pain again came on suddenly and was worse than before. She had to give up work and on the following day she attended at the Westminster Hospital. As regards her previous history the patient had an attack of broncho-pneumonia at the age of six years and she suffered from scarlet fever two and a half years before admission. There was no history of rheumatism. Her mother died from phthisis at the age of 32 years. Her father and brother were alive and healthy.

On admission the patient was very anæmic; the conjunctivæ were pale and the complexion was sallow. There was slight emaciation. The temperature varied, on the previous day being $102.8^{\circ} \mathrm{F}$., while now it was $98.2^{\circ}$. The pulse was 112 , full, quick, and soft. There was venous pulsation in the ressels of the neck; a thrill was felt at the base and apex of the heart; there was a mitral systolic murmur, best 